\title{
ОЦЕНКА ВОЗДЕЙСТВИЯ ТОПЛИВНО-ЭНЕРГЕТИЧЕСКОГО КОМПЛЕКСА ИРКУТСКОЙ ОБЛАСТИ НА ПРИРОДНУЮ СРЕДУ
}

\author{
Б. Г. Санеев, Е. П. Майсюк \\ Институт систем энергетики им. Л. А. Мелентьева, г. Иркутск, Российская Федерация
}

Информация о статье

Дата поступления

5 апреля 2018 г.

Дата принятия к печати

21 мая 2018 г.

Дата онлайн-размещения 8 июня 2018 г.

\section{Ключевые слова \\ Производство энергии; добыча топливно-энергетических ресурсов; водные объекты; атмосфера; отходы производства; экологические оценки}

\footnotetext{
Финансирование

Государственное задание на выполнение проекта СО РАН XI.174.1 «Многофракторное исследование развития ТЭК азиатских регионов страны в первой половине 21 века с учетом энергетической кооперации России со странами Северо-Восточной Азии». Регистрационный номер AAAA-A 17-117030310435-0 и частичная поддержка гранта РФфИ и правительства Иркутской области, проект № 17-48-380002 p_a
}

\begin{abstract}
Аннотация
В настоящее время в энергетике Прибайкалья одной из актуальных проблем является экологически чистое производство энергоресурсов. Анализ современной экологической ситуации в Иркутской области свидетельствует о ее неблагополучном состоянии на протяжении уже многих лет. В статье представлена сравнительная характеристика региональных и российских показателей воздействия хозяйственной деятельности на окружающую среду, обозначены основные источники эмиссии загрязняющих веществ в элементы природной среды. Мониторинг ряда целевых показателей государственной программы Российской Федерации “Охрана окружающей среды» на 2012-2020 гг. показал, что имеет место значительное превышение фактических данных, в связи с чем достижение плановых значений ставится под сомнение / вряд ли возможно. Выявлено, что наиболее существенное воздействие на атмосферу оказывают предприятия по производству электрической и тепловой энергии. Предприятия по добыче топливно-энергетических ресурсов в большей степени влияют на количество образования отходов производства и потребления. Проведение экологической оценки воздействия энергетики на природную среду позволяет сформулировать основные экологические проблемы и определить круг вопросов, требующих решения для дальнейшего развития энергетики Иркутской области.
\end{abstract}

\section{ASSESSMENT OF THE IMPACT OF FUEL AND ENERGY SECTOR OF THE IRKUTSK REGION ON THE ENVIRONMENT}

Boris G. Saneev, Elena P. Maysyuk

Melentiev Energy Systems Institute of Siberian Branch of the Russian Academy of Sciences, Irkutsk, the Russian Federation

Article info

Received

April 5, 2018

Accepted

May 21, 2018

Available online

June 8, 2018

\begin{abstract}
At the present time, one of the topical issues in the energy sector of the Baikal region is the ecologically clean production of energy resources. The analysis of the current ecological situation in the Irkutsk region reveals its unfavorable ecological state, which has been present for many years. The article draws a comparison of the impact indicators of economic activity in the region and in Russia, it also identifies the main sources of the environment pollution. Monitoring of a number of target indicators of the Russian Federation State Program on Environmental Protection for the period of 2012-2020 showed that there is a
\end{abstract}




\section{Keywords}

Energy generation; extraction of fuel and energy resources; water objects; atmosphere; production waste; environmental impact assessment

\section{Acknowledgements}

The research is conducted in the framework of the State assignment for the project SB RAS XI.174.1 «Multifactor Study of Fuel and Energy Industry Development of Asian regions in the first half of the 21 st century, taking into account the energy cooperation between Russia and Northeast Asia» reg. N AAAA A 17-117030310435-0 and partial support of RFBR grant and Government of the Irkutsk region № 17-48-380002 p_a

Топливно-энергетический комплекс Иркутской области. Энергетика в экономике области играет значительную роль и как важнейшая отрасль ее специализации, и как основа осуществления хозяйственной деятельности. Для выявления основных проблем при функционировании топливно-энергетического комплекса, которые могут сдерживать социально-экономическое развитие области, важен анализ его современного состояния.

Топливно-энергетический комплекс Иркутской области, включающий такие отрасли, как электро-, теплоэнергетика, угольная, нефтегазовая, нефтеперерабатывающая промышленность, производит более 50 \% промышленной продукции области [1, с. 177].

K топливно-энергетическому комплексу отнесены виды деятельности, которые связаны с производством электрической и тепловой энергии и добычей топливно-энергетических ресурсов.

На территории Иркутской области производство электрической и тепловой энергии осуществляется крупными энергообъектами (ТЭС, ГЭС, крупные котельные) и многочисленными мелкими котельными.

К крупным энергопроизводящим объектам отнесены предприятия ПАО «Иркутскэнерго» - Ангарский каскад ГЭС, 12 тепловых станций и 2 котельные (твердотопливная и газовая), а также 3 тепловых электростанции (ТЭЦ Братского лесопромышленного комплекса, ТЭЦ Усть-Илимского целлюлозного завода и ТЭЦ БЦБК), работающие на нужды теплоснабжения предприятий и населения городов.

Кроме того, к объектам энергетики отнесены многочисленные источники производства тепловой энергии - котельные. $\mathrm{Ha}$ территории области функционирует более 1100 котельных различной мощности, большинство из которых - котельные с котлами малой мощности без устройств очистки уходящих газов (91 \% от всех угольных котельных).

К предприятиям, связанным с добычей топливно-энергетических ресурсов на территории области, относятся компании, добывающие уголь, нефть, природный газ и газовый конденсат, а также предприятия нефтепереработки. Основным угледобывающим предприятием является ООО «Компания «Востсибуголь» с тремя фрилиалами («Разрез Черемховуголь», «Разрез «Тулунуголь» и «Разрез Жеронский»).

Нефте- и газодобычей в регионе занимается порядка десяти компаний. Наиболее крупные из них - ООО «Иркутская нефтяная компания» и ПАО «Вехнечонскнефтегаз». Нефтепереработку углеводородов на территории области осуществляет $\mathrm{AO}$ «Ангарская нефтехимическая компания», входящая в структуру ПАО «НК «Роснефть».

Оценка воздействия топливно-энергетического комплекса на элементы природной среды связана прежде всего с выявлением экологических проблем, что позволит проводить многофракторные исследования в части экологически чистого развития энергетики Иркутской области. 
Экологическая ситуация в области. На фоне основных показателей воздействия хозяйственной деятельности на окружающую среду в 2016 г. Иркутская область существенно выделяется среди регионов Сибирского федерального округа (рис. 1)'.

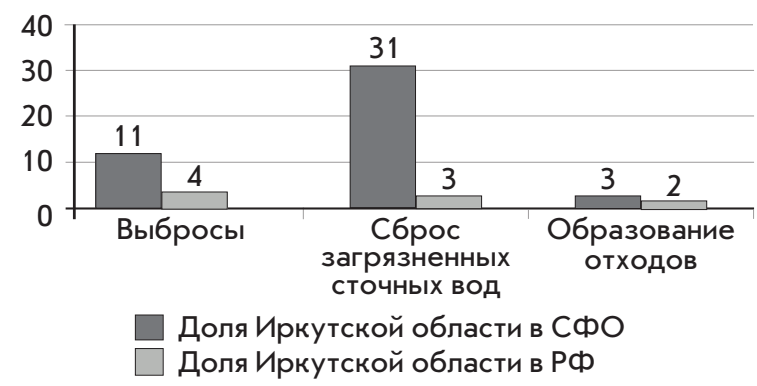

Рис. 1. Доля Иркутской области в воздействии на окружающую среду, \%

Рассматривая аналогичные показатели (на душу населения по состоянию на 2016 г. (рис. 2)), следует отметить, что в сравнении со среднероссийскими показателями в Иркутской области превышение наблюдается по всем значениям: по выбросам в атмосферу от стационарных источников - в 2,3 раза, по стокам загрязненных вод - в 2,1 раза, по образованию отходов производства и потребления - в 1,5 раза.

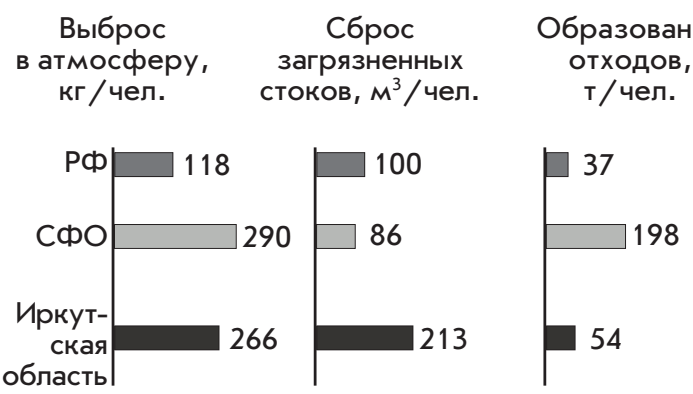

Рис. 2. Удельные показатели воздействия (на дүшу населения) на элементы природной среды в Иркутской области, СФО и России

Общая характеристика воздействия хозяйственной деятельности на элементы природной среды в Иркутской области в 2015-2016 г. приведена в табл. 1.

URL: http://www.mnr.gov.ru/docs/o sostoyanii_i_ob_okhrane_okruzhayushchey_sredy_ rossiyskoy_federatsii/gosudarstvennyy_doklad_o_ sostoyanii_i_ob_okhrane_okruzhayushchey_sredy_ rossiyskoy_federatsii_v_2016_/; URL: http://irkobl. $\mathrm{ru} / \mathrm{sites} /$ ecology/макет.pdf.
Таблица 1

Характеристика воздействия хозяйственной деятельности на окружающую среду в Иркутской области

\begin{tabular}{|c|c|c|c|c|}
\hline Показатель & $\begin{array}{c}\text { Единица } \\
\text { измере- } \\
\text { ния }\end{array}$ & 2015 & 2016 & $\begin{array}{l}\text { Рост }(\uparrow), \\
\text { сниже- } \\
\text { ние }(\downarrow)\end{array}$ \\
\hline \multicolumn{5}{|c|}{ Aтмосфрера } \\
\hline $\begin{array}{l}\text { Выброс вредных } \\
\text { веществ (стацио- } \\
\text { нарные источники) }\end{array}$ & тыс. т & 639 & 642 & $\uparrow$ \\
\hline $\begin{array}{l}\text { Доля уловленных } \\
\text { и обезвреженных } \\
\text { загрязняющих } \\
\text { веществ }\end{array}$ & $\%$ & 79,6 & 76,6 & $\downarrow$ \\
\hline $\begin{array}{l}\text { Выброс загрязняю- } \\
\text { щих веществ } \\
\text { от автотранспорта }\end{array}$ & тыс. т & 187 & 202 & $\uparrow$ \\
\hline $\begin{array}{l}\text { Вклад автотран- } \\
\text { спорта в суммар- } \\
\text { ный выброс }\end{array}$ & $\%$ & 22,5 & 24,0 & $\uparrow$ \\
\hline \multicolumn{5}{|c|}{ Водные объекты } \\
\hline $\begin{array}{l}\text { Использовано } \\
\text { свежей воды }\end{array}$ & млн м $^{3}$ & 829 & 802 & $\downarrow$ \\
\hline Сбросы сточных вод & млн м $^{3}$ & 807 & 790 & $\downarrow$ \\
\hline $\begin{array}{l}\text { В том числе } \\
\text { загрязненных }\end{array}$ & млн м $^{3}$ & 507 & 514 & $\uparrow$ \\
\hline $\begin{array}{l}\text { Из них без } \\
\text { очистки }\end{array}$ & млн м $^{3}$ & 83 & 87 & $\uparrow$ \\
\hline \multicolumn{5}{|c|}{ Отходы производства и потребления } \\
\hline $\begin{array}{l}\text { Образовалось } \\
\text { отходов }\end{array}$ & млн т & 120 & 130 & $\uparrow$ \\
\hline $\begin{array}{l}\text { Использовано } \\
\text { и обезврежено }\end{array}$ & млн т & 156 & 114 & $\downarrow$ \\
\hline $\begin{array}{l}\text { Доля использования } \\
\text { и обезвреживания } \\
\text { отходов }\end{array}$ & $\%$ & 130 & 87 & $\downarrow$ \\
\hline
\end{tabular}

В области основными источниками выбросов в атмосферу являются предприятия энергетики, металлургии, лесной и деревообрабатывающей промышленности, предприятия химической, нефттехимической отраслей. Также на загрязнение воздушного бассейна влияет большое количество мелких котельных, жилой сектор с печным отоплением, автотранспорт, лесные и торфряные пожары ${ }^{2}$.

Необходимо отметить, что наряду с промышленными предприятиями загрязняют атмосферный воздух и передвижные источники (в 2016 г. их доля составила $24 \%$, и имеется тенденция к ее росту).

Основными поставщиками загрязненных сточных вод являются предприятия золотодобывающей, целлюлозно-бумажной, химической и нефртехимической промышленности, угле- и нефтедобычи, а также объекты ЖКХ. За последние два года при снижении использо-

${ }^{2}$ URL: http://irkobl.ru/sites/ecology/ макет.pdf. 
вания свежих вод и сбросов сточных вод увеличился объем загрязненных стоков, в том числе и поступающих в водоемы стоков без очистки.

В целом, характеризуя экологическую ситуацию в Иркутской области, следует отметить, что она продолжает оставаться неблагополучной, а проводимых в каждой сорере хозяйствования природоохранных мер недостаточно. Учитывая целевые показатели госпрограммы «Охрана окружающей среды» на 2012-2020 гг. ${ }^{3}$, можно отметить, что возможность их достижения (по объемам выбросов, доле уловленных и обезвреженных загрязняющих веществ, объемам образованных отходов) вызывает сомнение (табл. 2).

Таблица 2

Достижение целевых показателей госпрограммы «Охрана окружающей среды» по состоянию на 2016 г. в Иркутской области“

\begin{tabular}{|l|r|r|r|}
\hline \multicolumn{1}{|c|}{ Показатель } & План & Факт & $\begin{array}{l}\text { Превышение, } \\
\text { раз }\end{array}$ \\
\hline $\begin{array}{l}\text { Выбросы от стацио- } \\
\text { нарных источников, } \\
\text { \% к 2007 г. }\end{array}$ & 108,7 & 115,9 & 1,1 \\
\hline $\begin{array}{l}\text { Доля уловленных } \\
\text { и обезвреженных } \\
\text { загрязняющих } \\
\text { веществ, \% }\end{array}$ & 82,9 & 76,6 & 1,1 \\
\hline $\begin{array}{l}\text { Объем образован- } \\
\text { ных отходов, } \\
\text { \% к 2007 г. }\end{array}$ & 45,2 & 139,0 & 3,1 \\
\hline
\end{tabular}

В программе в качестве целевых приняты показатели 2007 г.

\section{Воздействие предприятий топливно-} энергетического комплекса. Наиболее значительное воздействие на элементы природной среды оказывают предприятия топливно-энергетического комплекса.

Крупные энергоисточники. От предприятий ПАО «Иркутскэнерго» в 2016 г. в атмосферу поступило 263,5 тыс. т загрязняющих веществ ${ }^{4}$. Преимущественно это выбросы крупных ТЭЦ и двух котельных, выбросыГЭС составили 11 т (менее 0,01\%).

В настоящее время, как и в прошлые годы, одной из экологических проблем является существенный выброс в атмосфреру оксидов серы. Так, в 2016 г. из 204 тыс. т выбросов SO 172,2 тыс. т (или 84 \% от суммарных выбросов оксидов серы в области) - это только выбросы от предприятий ПАО «Иркутскэнерго».

Для улавливания загрязняющих веществ в энергосистеме на 100 эксплуатирующихся паровых энергетических и 10 водогрейных котлах установлены золоулавливающие уста-

${ }^{3}$ URL: http://www.mnr.gov.ru/regulatory/detail. php?ID=130036.

${ }^{4}$ URL: http: //irkobl.ru/sites/ecology/ макет.pdf. новки различных типов. Их средняя эфффективность по очистке от твердых частиц в 2016 г. составила 96,2\%5.

Среднегодовой расход сточных вод на предприятия ПАО «Иркутскэнерго» составил 221,9 млн м³, со стоками которых в водные объекты поступило 7,1 тыс. т загрязняющих веществ $^{6}$. Из суммарных сбросов сточных вод загрязненные стоки составили 56,6 млн м ${ }^{3}$ (или $26 \%$ ).

В 2016 г. на предприятиях компании образовалось 1353 тыс. т отходов производства и потребления, из них 98,5 \% - золошлаковые отходы, которые в количестве 620,3 тыс. т реализованы и использованы (51 \%). На конец 2016 г. в компании накоплено 86,6 млн т отходов производства и потребления.

Для оценки воздействия на элементы природной среды трех тепловых станций Братского лесопромышленного комплекса, Усть-Илимского целлюлозного завода и Байкальского целлюлозно-бумажного комбината - проведены расчеты выбросов загрязняющих веществ в атмосореру с использованием существующих и утвержденных правительством методик ${ }^{7}$. В соответствии со статистическими формами (6-ТП) расход топлива на ведомственных станциях в 2016 г. составил 1,6 млн т условного топлива ${ }^{8}$. Причем на станциях Братского и Усть-Илимского лесопромышленного комплекса сжигаются отходы лесопереработки в объеме 700 и 814 тыс. т условного топлива соответственно. На тепловой станции Байкальска используется черемховский каменный уголь в объеме 55,2 тыс. т условного топлива.

В соответствии с методикой расчет проводится для трех основных вредных ингредиентов, характерных для объектов энергетики: твердых веществ, оксидов серы и азота. В расчетах в среднем принята степень очистки уходящих газов от пыли на $90 \%$. Для станций лесопромышленного комплекса значения топочных характеристик приняты в соответствии с рекомендациями по сжиганию древесных отходов прямым сжиганием, в том числе и в кипящем слое?.

${ }^{5}$ URL: http: / / www.irkutskenergo.ru/qa/22.2.html.

${ }^{6}$ URL: http://www.irkutskenergo.ru/gi/24163.

${ }^{7}$ Сборник методик по расчету выбросов в атмосферу загрязняющих веществ различными производными / Гос. ком. СССР по гидрометеорологии и контролю природ. среды. Л. : Гидрометеоиздат, 1986. 183 с. ; Методика определения валовых выбросов загрязняющих веществ в атмосферу от котельных установок ТЭС. РД 34.02.305-98. M., 1998. 35 c.

${ }^{8}$ Формы Росстата 6-ТП. Расход топлива ТЭС в Иркутской области в 2016 г.

9 URL: http://www.energoportal.ru/articles/ prakticheskij-primer-rekonstrukcii-kotla-e-19-s-perevodomna-szhiganie-1909.html. 
Расчеты показали, что от трех ТЭЦ в 2016 г. в атмосферу поступило 17,8 тыс. т загрязняющих веществ с преимущественной эмиссией твердых частиц.

Поскольку данных об объемах сточных вод и количестве отходов от рассматриваемых энергоисточников не опубликовано, воспользуемся удельными показателями компании ПАО «Иркутскэнерго». Соответственно, расчетный сброс загрязненных сточных вод может составить 14,9 млн м³.

Расчет объемов образования золошлаковых отходов проводится на основе рекомендаций, данных в [2; 3]. В 2016 г. по названным трем станциям суммарный объем золошлаковых отходов оценивается в 70 тыс. т, в том числе от угольной станции в Байкальске - до 10 тыс. т, от станции в Братске - 27,2 тыс. т и в Усть-Илимске - 31,3 тыс. т.

Дизельные электростанции. Оценка воздействия автономных и передвижных дизельных электростанций (ДЭС) на элементы природной среды проводится только с позиции их вклада в выброс загрязняющих веществ в атмоссреру. Определение количества выбросов осуществляется на основе указаний, содержащихся в Методике расчета выбросов загрязняющих веществ в атмосферу от стационарных дизельных установок ${ }^{10}$, в которой для различных групп ДЭС заданы удельные выбросы для семи загрязняющих ингредиентов. Для расчетов выбросов от ДЭС Иркутской области авторами установлено, что подавляющее большинство дизельных установок прошли капитальный ремонт и относятся к категории малой и средней мощности. Исходя из годовой потребности в дизельном топливе автономных и передвижных электростанций области в 35-40 тыс. т расчетный выброс составит от 1,4 до 1,8 тыс. т в год.

Котельные. Оценка воздействия на природную среду котельных приводится в зависимости от объемов сожженного топлива, в результате чего определяется количество выбросов загрязняющих веществ в атмосферу и рассчитывается объем золошлаковых отходов.

Общий объем потребления угля в 2016 г. составил 2 млн 61 тыс. т ${ }^{11}$. Очистка уходящих газов в расчетах количества выбросов загрязняющих веществ в атмосферу учитывается в зависимости от типа и мощности котловых агрегатов, установленных в котельных. В

10 Методика расчета выбросов загрязняющих веществ в атмосферу от стационарных дизельных установок. СПб. : НИИ Атмосфера, 2001. 18 с.

11 Формы Росстата 4-ТЭР. Расход топлива по видам топлива в Иркутской области, 2016 г. целом авторами принято, что в котельных с котлами малой мощности и ручной подачей топлива очистка отсутствует, так же как и для установок средней мощности (от 1 до 10 Гкал в час) с механизированной подачей топлива и топкой с шурующей планкой. Котельные агрегаты с механизированной подачей топлива и цепной решеткой конструкционно связаны с циклонами разного типа (одиночные, батарейные) и имеют в среднем степень очистки от твердых частиц до $80 \%$. В крупных котельных с котлами мощностью более 10 Гкал в час принята степень очистки от твердых частиц на $90 \%$.

Расчет выбросов котельными области проведен с использованием Методики определения выбросов загрязняющих веществ в атмосферу при сжигании топлива в котлах производительностью менее 30 т пара в час или менее 20 Гкал в час ${ }^{12}$ и оценивается в 121,2 тыс. т в 2016 г.

Образование золошлаковых отходов от котельных при сжигании угля и древесного топлива оценивается в 250 тыс. т в 2016 г.

Объем загрязненных стоков рассчитан только для крупных котельных и может составить 8,9 млн м³ в 2016 г.

Таким образом, объекты, производящие тепловую и электрическую энергию, поставляют в атмосферу 72,0 \% от суммарных выбросов Иркутской области, 15,6 \% всех сбросов загрязненных стоков (табл. 3).

Таблица 3

Оценка воздействия на элементы природной среды предприятий по производству электрической тепловой энергии (состояние на 2016 г.)

\begin{tabular}{|l|r|r|r|}
\hline $\begin{array}{c}\text { Объекты произ- } \\
\text { водства тепловой } \\
\text { и электрической } \\
\text { энергии }\end{array}$ & $\begin{array}{c}\text { Вы- } \\
\text { бросы, } \\
\text { тыс. т }\end{array}$ & $\begin{array}{c}\text { Сбросы } \\
\text { загрязнен- } \\
\text { ных вод, } \\
\text { млн м }\end{array}$ & $\begin{array}{c}\text { Отходы } \\
\text { произ- } \\
\text { водства, } \\
\text { млн т }\end{array}$ \\
\hline $\begin{array}{l}\text { ПАО «Иркутск- } \\
\text { энерго» }\end{array}$ & 263,4 & 56,6 & 1,40 \\
\hline ТЭЦ предприятий & 17,7 & 14,9 & 0,07 \\
\hline Котельные & 121,2 & 8,9 & 0,25 \\
\hline ДЭС & 1,8 & - & - \\
\hline \multicolumn{1}{|c|}{ Всего } & 404,1 & 80,4 & 1,72 \\
\hline
\end{tabular}

12 Методика определения выбросов загрязняющих веществ в атмосферу при сжигании топлива в котлах производительностью менее 30 тонн пара в час или менее 20 Гкал в час. М. : Гос. ком. по охране окружающей среды РФ, 1999. 53 с. ; О проведении расчетов выбросов вредных веществ в атмосферу по «Методике определения выбросов загрязняющих веществ в атмосферу при сжигании топлива в котлах производительностью менее 30 тонн пара в час или менее 20 Гкал в час» : метод. письмо НИИ Атмосфера от 17 мая 2000 г. № 335/3307. URL: http: //docs.cntd.ru/document/1200008291. 
На атмосфреру оказывается существенное воздействие, при этом 69,5\% от суммарных выбросов поставляют крупные энергопредприятия и 30 \% - котельные. Ингредиентная структура выбросов характеризуется неравнозначностью. Так, в выбросах ТЭС ПАО «Иркутскэнерго» преобладают оксиды азота (65\%), в выбросах крупных ТЭЦ предприятий и котельных - твердые частицы (50 и 92 \% соответственно) (рис. 3, а), тогда как в среднем по области выброс твердых частиц оценивается в 38 \% от общих выбросов данной категории энергообъектов, оксидов серы - 50 \%, оксидов азота - $12 \%$ (рис. 3, б).

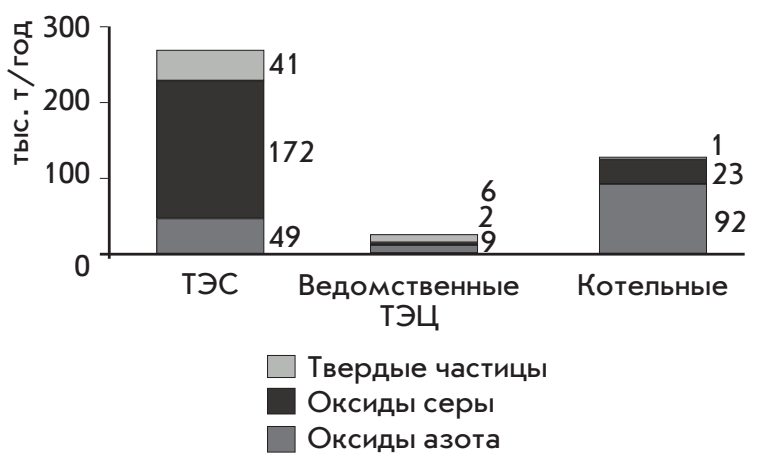

a

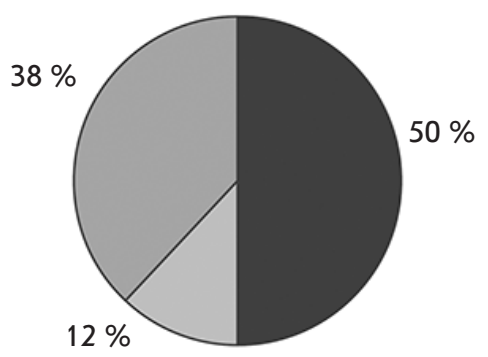

$\square$ Твердые частицы

Оксиды серы

Оксиды азота

6

Рис. 3. Ингредиентная структура выбросов от объектов по производству электрической и тепловой энергии: а - тЭС, 6 - тЭЦ и котельных

Предприятия по добыче и переработке топливно-энергетических ресурсов. Для оценки воздействия на элементы природной среды предприятий топливодобывающей промышленности в Иркутской области проведены укрупненные оценки, использованы статистические данные и годовые отчеты топливодобывающих предприятий, а также справочные данные по удельным показателям воздействия на природную среду ${ }^{13}$ [4].

13 URL: http://www.waste.ru/uploads/library/ specific_showing.pdf.
В целом воздействие на элементы природной среды отраслей по производству топливно-энергетических ресурсов и их переработке представлено в табл. 4. В сравнении с соответствующими показателями по Иркутской области вклад этих предприятий составил: в выбросы вредных веществ в атмосфреру - 20,1% (от суммарных в области), в сбросы загрязненных стоков - 3,6 \%, в образование отходов производства и потребления - 26,0\%.

Таблица 4

Оценка воздействия на элементы природной среды отраслей по производству топливно-энергетических ресурсов и их переработке (состояние на 2016 г.)

\begin{tabular}{|l|r|r|r|}
\hline \multicolumn{1}{|c|}{ Отрасль } & $\begin{array}{c}\text { Выбросы, } \\
\text { тыс. т }\end{array}$ & $\begin{array}{c}\text { Сбросы } \\
\text { загрязнен- } \\
\text { ных вод, } \\
\text { млн м }\end{array}$ & $\begin{array}{c}\text { Отходы } \\
\text { произ- } \\
\text { водства, } \\
\text { млн т }\end{array}$ \\
\hline Угледобыча & 4,6 & 6,0 & 36,2 \\
\hline $\begin{array}{l}\text { Добыча углево- } \\
\text { дородного сырья }\end{array}$ & 101,7 & 5,1 & 0,4 \\
\hline $\begin{array}{l}\text { Переработка } \\
\text { нефти }\end{array}$ & 23,0 & 7,4 & 0,04 \\
\hline \multicolumn{1}{|c|}{ Всего } & 129,3 & 18,5 & 36,6 \\
\hline
\end{tabular}

Ингредиентная структура выбросов топливодобывающих и перерабатывающих предприятий характеризуется преобладанием газообразных выбросов.

Оценка вклада топливно-энергетического комплекса в воздействие на природную среду. В целом воздействие объектов энергетики области на элементы природной среды представлено в табл. 5. В ней показано, что производство электрической и тепловой энергии оказывает наибольшее влияние на атмосферу и водные объекты. Добыча топливно-энергетических ресурсов (угля и углеводородов) связана с образованием значительного количества отходов производства и потребления.

Таблица 5

Воздействие объектов топливноэнергетического комплекса области на элементы природной среды в 2016 г.

\begin{tabular}{|c|c|c|c|}
\hline $\begin{array}{c}\text { Топливно- } \\
\text { энергетический } \\
\text { комплекс }\end{array}$ & $\begin{array}{c}\text { Выбросы, } \\
\text { тыс. т }\end{array}$ & $\begin{array}{c}\text { Сбросы } \\
\text { загрязнен- } \\
\text { ных вод, } \\
\text { млн м }\end{array}$ & $\begin{array}{c}\text { Отходы } \\
\text { произ- } \\
\text { водства, } \\
\text { млн т } \\
\end{array}$ \\
\hline $\begin{array}{l}\text { Производство } \\
\text { электрической } \\
\text { и тепловой } \\
\text { энергии }\end{array}$ & 404,1 & 80,4 & 1,72 \\
\hline $\begin{array}{l}\text { Добыча } \\
\text { и переработка } \\
\text { топливно- } \\
\text { энергетических } \\
\text { ресурсов }\end{array}$ & 129,3 & 18,5 & 36,60 \\
\hline Всего & 533,4 & 98,9 & 38,32 \\
\hline
\end{tabular}


Таким образом, вклад топливно-энергетического комплекса Иркутской области в 2016 г. по показателям воздействия на элементы природной среды оценивается в 83 \% от суммарных выбросов загрязняющих веществ в атмосфреру, в сброс загрязненных стоков в водные объекты - в 19 \% и образование отходов производства и потребления - до $30 \%$ (рис. 4).

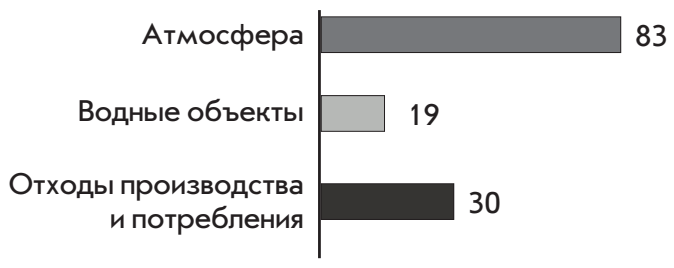

Рис. 4. Вклад объектов топливноэнергетического комплекса в воздействие на элементы природной среды, \%

Выводы. Проведенное исследование по оценке воздействия топливно-энергетического комплекса Иркутской области на природную среду позволяет выявить основные экологические проблемы. Наибольшему влиянию подвергается атмосфера. Одной из причин является недостаточная степень очистки выбросов, которая в среднем по области в 2016 г. составила 76,6 \% (и имеет тенденцию к снижению). Если крупные ТЭЦ оснащены золоулавливающими устройствами и имеют достаточно высокую степень очистки (в среднем по области до 90-92 \%), то более 65 \% многочисленных котельных области функционирует без них. Существенная проблема - выброс крупными энергообъектами диоксида серы, способного включаться в дальний перенос и, окисляясь, выпадать в виде кислотных дождей. При этом на территории области находится уни- кальный природный объект - озеро Байкал, что требует особого внимания со стороны «высоких» газовых выбросов от крупных энергопредприятий и «низких» источников эмиссии, расположенных в прибрежной зоне (центральной экологической зоне) озера. Важно отметить, что до сих пор органами статистики не охвачена такая значительная категория объектов ТЭК, как средние и малые котельные.

Основной причиной сброса загрязненных стоков является недостаточная мощность очистных сооружений, не обеспечивающих надлежащую очистку вод, износ оборудования и использование его на предельной загрузке. Прежде всего это относится к предприятиям, осуществляющим сбор, очистку и перераспределение воды. Фактически без очистки в поверхностные водотоки поступают смывные воды предприятий угледобычи. В государственных докладах и отчетах компаний по добыче углеводородов в Иркутской области отсутствуют данные по объему сброса загрязненных сточных вод, что осложняет проведение экологических оценок.

Вклад отраслей топливно-энергетического комплекса Иркутской области в образование отходов производственной деятельности связан с образованием золошлаковых отходов при сжигании углей, однако существенную долю образуют отходы угледобычи, хоть и являются преимущественно отходами $\mathrm{V}$ класса опасности (практически неопасными).

Обозначенные выше экологические проблемы требуют всестороннего многофакторного анализа при разработке специальных мер как технологического, так и организационного характера для экологически чистого развития топливно-энергетического комплекса Иркутской области.

\section{СПИСОК ИСПОЛЬЗОВАННОЙ ЛИТЕРАТУРЫ}

1. Топливно-энергетический комплекс Иркутской области и его влияние на природную среду / Б. Г. Санеев [и др.] // Актуальные проблемы науки Прибайкалья / ред. И. В. Бычков, А. Л. Казаков. - Иркутск, 2017. Вып. 2. - С. 175-180.

2. Сидельковский Л. Н. Котельные установки промышленных предприятий : учебник / Л. Н. Сидельковский, В. Н. Юренев. - 3-е изд., перераб. - М. : Энергоатомиздат, 1988. - 528 с.

3. Назмеев Ю. Г. Системы золошлакоудаления ТЭС / Ю. Г. Назмеев. - М. : Изд-во МЭИ, 2002. - 572 с.

4. Справочник по удельным показателям выбросов загрязняющих веществ в атмосферу для некоторых производств - основных источников загрязнения атмосферы / А. Н. Ясенский [и др.]. - 3-е изд. - СПб., 2001. $-116 \mathrm{c}$.

\section{REFERENCES}

1. Saneev B. G., Sokolov A. D., Muzychuk S. Yu., Maysyuk E. P. Fuel and energy complex of the Irkutsk region and its influence on the natural environment. In Bychkov I. V., Kazakov A. L. (eds.). Aktualnye problemy nauki Pribaikalya [Topical Issues of the Science in the Baikal Region]. Irkutsk, 2017, vol. 2, pp. 175-180. (In Russian).

2. Sidelkovskii L. N., Yurenev V. N. Kotelnye ustanovki promyshlennykh predpriyatii [Boiler Plants of Production Enterprises]. $3^{\text {rd }}$ ed. Moscow, Energoatomizdat Publ., 1988. 528 p. 
3. Nazmeev Yu. G. Sistemy zoloshlakoudaleniya TES [Ash and Slag Removal Systems of a Thermal Electric Power Plant]. Moscow, MEl Publ., 2002. 572 p.

4. Yasenskii A. N. et al. Spravochnik po udelnym pokazatelyam vybrosov zagryaznyayushchikh veshchestv $v$ atmosferu dlya nekotorykh proizvodstv — osnovnykh istochnikov zagryazneniya atmosfery [Reference Book on Relative Indicators of Emission of Pollutants into the Environment for Some Production Enterprises — the Main Air Pollution Sources]. $3^{\text {rd }}$ ed. Saint Petersburg, 2001. 116 p.

\section{Информация об авторах}

Санеев Борис Григорьевич - доктор техни ческих наук, профессор, заместитель директора, Институт систем энергетики им. Л. А. Мелентьева СО РАН, 664033, г. Иркутск, ул. Лермонотова, 130, e-mail: saneev@isem.irk.ru.

Майсюк Елена Петровна — кандидат экономических наук, старший научный сотрудник лаборатории энергоснабжения децентрализованных потребителей, Институт систем энергетики им. Л. А. Мелентьева СО РАН, Иркутск, 664033, г. Иркутск, ул. Лермонотова, 130, e-mail: maysyuk@isem.irk.ru.

\section{Для цитирования}

Санеев Б. Г. Оценка воздействия топливноэнергетического комплекса Иркутской области на природную среду / Б. Г. Санеев, Е.П.Майсюк // Известия Байкальского государственного университета. - 2018. - T. 28, № 2. - C. 249-256. - DOI: $10.17150 / 2500-2759.2018 .28(2) .249-256$.

\section{Authors}

Boris G. Saneev - D.Sc. in Engineering Science, Professor, Deputy Director, Melentiev Energy Systems Institute of Siberian Branch of the Russian Academy of Sciences, 130 Lermontov St., 664033, Irkutsk, the Russian Federation, e-mail: saneev@isem.irk.ru.

Elena P. Maysyuk - Ph.D. in Economics, Senior researcher of the Laboratory of Energy Supply for Distributed Consumers, Melentiev Energy Systems Institute of Siberian Branch of the Russian Academy of Sciences, 130 Lermontov St., 664033, Irkutsk, the Russian Federation, e-mail: maysyuk@isem.irk.ru.

\section{For citation}

Saneev B. G., Maysyuk E. P. Assessment of the Impact of Fuel and Energy Sector of the Irkutsk Region on the Environment. Izvestiya Baykal'skogo gosudarstvennogo universiteta $=$ Bulletin of Baikal State University, 2018, vol. 28, no. 2, pp. 249-256. DOI: 10.17150/2500-2759.2018.28(2).249-256. (In Russian). 